\title{
Analysis of Investment Appeal for the Food Industry of Crimea
}

\author{
Tatiana Lomachenkoㅇ, Remzi Ablaev ${ }^{2, *}$, Alim Ablaev $^{2}$, Stanislav Roshchupkin ${ }^{2}$ \\ ${ }^{I}$ Department of Economics, Finance, and Accounting Sevastopol Affiliate of the Plekhanov Russian Economic \\ University, Sevastopol 299053, Russia \\ ${ }^{2}$ Sevastopol State University, Sevastopol 299053, Russia \\ "Corresponding author.Email: Ablaev.expert@mail.ru
}

\begin{abstract}
This research seeks to develop a generalized investment appeal indicator for a food company and for the food industry of a region by the example of Crimea. The latter is further called the rating of investment appeal for a region. Being of interest to management scholars and practitioners, the formulated indicators are calculated using the database of the main financial and activity indicators for Crimean food companies (2015-2019). Keywords: principle component analysis, investment appeal, food industry
\end{abstract}

\section{INTRODUCTION}

A significant increase in the complexity of somewhat chaotic changes in food production and consumption that we observe today resulted from intense economic, scientific, technical, and demographic development of modern civilization and its environmental consequences, such as global pollution and depletion of the natural resources $[1,2]$. Wide application of innovative methods of molecular chemistry and physics, genetic engineering technologies, nanotechnologies, and other contemporary advances of fundamental sciences in the food industry insures the rapid increase in the number of available consumer food choices, such as functional, dietary, organic, genetically modified, and other products [3, 4]. To sustain and increase the innovative level of food industry, significant amount of investment is required [5, $6,7]$. Thus, it is vital to develop a generalized investment appeal indicator both for a food company and for the food industry in order to provide an investor with a practical tool to rank companies and regions by their investment appeal.

\subsection{Materials and Methods}

\subsubsection{Sample for analysis}

A total of 13 randomly selected Crimean food companies were analyzed using information provided by the Ukrainian State Statistics Committee. Historical statistical data on the six major efficiency indicators for these companies (the number of customers, net assets, sales volume, balance profit, budget payments and costs) was extracted from this database for further analysis.

\subsubsection{Calculating the generalized investment appeal indicator}

The generalized investment appeal indicator was obtained using the Principal Component Analysis (PCA) in the Open Source Software - GRETL - by calculating the first principle component based on the six initial efficiency indicators of the sample. That is, the PCA was applied in order to provide a generalization of initial company efficiency indicators into one aggregated indicator in order to obtain a possibility to compare or rank various food companies by the level of their investment appeal.

\subsubsection{Analyzing dynamics of the investment appeal indicator for the food industry}

Trend analysis (one of the econometrics methods) was used to estimate the dynamics of the general investment appeal indicator (rating) for the food industry. The latter was obtained by calculating Eigen values for the first principle components corresponding to investment appeal indicators for each year. That is, the trend analysis was used to analyze and project dynamics of the suggested aggregated investment appeal indicator (rating) for the region.

\section{RESULTS}

Within this study, the goal was achieved to develop such a rating of investment appeal for a region, using econometric methods, that it would be used as a universal tool of the overall independent assessment of the current state and potential of a region's food industry. The rating also provides the key information for an investor regarding 
contains the majority of information about the company from $x_{1}, \ldots, x_{6}$.

$$
y_{1}(x)=w_{11}\left(\frac{x_{1}-\bar{x}_{1}}{\sigma_{1}}\right)+\ldots+w_{61}\left(\frac{x_{6}-\bar{x}_{6}}{\sigma_{6}}\right),
$$

where $\bar{x}_{j}$ and $\sigma_{j}$ - the average and standard deviation of $\mathrm{xj} ; w_{\mathrm{j} 1}-$ coefficients of the most significant principal component $\left(\sum_{j=1}^{6} w_{\mathrm{j} 1}^{2}=1\right) ; y_{1}-$ the most significant principal component - a generalized index of the investment appeal for a company.

The value $\lambda_{1}$ is the maximum eigenvalue for the first principal component $y_{1}$. As far as $\lambda_{1}$ generalizes the majority of observations $x_{1}, \ldots, x_{6}$, it can be considered the rating of investment appeal for a region in a given year and further used to track the dynamics of a region's investment appeal.

According to the modeling results obtained in Gretl (figure 1), the generalized indicator of investment appeal for a company (y1) for the year 2019 is determined using formula (2):

$$
\begin{aligned}
& Y 1_{2019}=0,452 \cdot \text { ClientBase }+0,428 \cdot N A+ \\
& +0,459 \cdot \text { SalesVolume }+0,453 \cdot \text { Costs }+ \\
& +0,152 \cdot \text { BalanceProfit }+0,416 \cdot \text { BudgetPayments. }
\end{aligned}
$$

\begin{tabular}{|c|c|c|c|}
\hline Component & Eigenvalue & Proportion & Cumulativ \\
\hline$<1$ & 4,3593 & 0,7265 & 0,7265 \\
\hline 2 & 0,9329 & 0,1555 & 0,8820 \\
\hline 3 & 0,3859 & 0,0643 & 0,9463 \\
\hline 4 & 0,2813 & 0,0469 & 0,9932 \\
\hline 5 & 0,0394 & 0,0066 & 0,9998 \\
\hline 6 & 0,0013 & 0,0002 & 1,0000 \\
\hline
\end{tabular}

\begin{tabular}{|c|c|c|c|c|c|c|}
\hline Variable & & $\mathrm{PC} 2$ & $\mathrm{PC} 3$ & $\mathrm{PC} 4$ & $\mathrm{PC} 5$ & PC6 \\
\hline Client_base & 0,452 & $-0,052$ & 0,236 & 0,485 & $-0,708$ & $-0,019$ \\
\hline NA & 0,428 & $-0,063$ & 0,684 & 0,105 & 0,576 & 0,044 \\
\hline Sales_Volume & 0,459 & 0,001 & $-0,153$ & $-0,503$ & $-0,122$ & 0,706 \\
\hline Costs & 0,453 & $-0,161$ & $-0,116$ & $-0,513$ & $-0,071$ & $-0,698$ \\
\hline Balance_Profit & 0,152 & 0,982 & $-0,004$ & $-0,020$ & 0,012 & $-0,113$ \\
\hline BudgetPāym & & $-0,062$ & $-0,664$ & 0,486 & 0,382 & $-0,002$ \\
\hline
\end{tabular}

Principal Components Analysis

Eigenvectors (component loadings)

Figure 1. Modeling results in Gretl using the Principal Components Method for the year 2019 
The per cent of initial data $x_{1}, \ldots, x_{6}$ embraced by $y 1$ and included into the formula (2) is $72,65 \%$ (Proportion on figure 1).

Thus, eigenvalue $\lambda_{2019}=4,3593$ can be considered the rating of investment appeal for a region in 2019.

Similar calculations were conducted using 2018data (figure 2), formula (3) was obtained:

$$
\begin{aligned}
& Y 1_{2018}=0,457 \cdot \text { ClientBase }+0,434 \cdot N A+ \\
& +0,451 \cdot \text { SalesVolume }+0,453 \cdot \text { Costs }+ \\
& +0,06 \cdot \text { BalanceProfit }+0,436 \cdot \text { BudgetPayments } .
\end{aligned}
$$

The per cent of initial data $x_{1}, \ldots, x_{6}$ embraced by y1 and included into the formula (3) is $74,49 \%$ (Proportion on figure 2).

Thus, eigenvalue $\lambda_{2018}=4,4692$ can be considered the rating of investment appeal for a region in 2017.

Similar calculations were conducted using 2017 data (figure 3), formula (4) was obtained:

\begin{tabular}{|c|c|c|c|}
\hline \multicolumn{4}{|c|}{ Eigenanalysis of the Correlation Matrix } \\
\hline Component & Eigenvalue & Proportion & Cumulative \\
\hline-1 & 4,4692 & 0,7449 & 0,7449 \\
\hline 2 & 0,9921 & $\overline{0,1654}$ & 0,9102 \\
\hline 3 & 0,2860 & 0,0477 & 0,9579 \\
\hline 4 & 0,2130 & 0,0355 & 0,9934 \\
\hline 5 & 0,0387 & 0,0065 & 0,9998 \\
\hline 6 & 0,0010 & 0,0002 & 1,0000 \\
\hline
\end{tabular}

$Y 1_{2017}=0,447 \cdot$ ClientBase $+0,446 \cdot N A+$

Eigenvectors (component loadings)
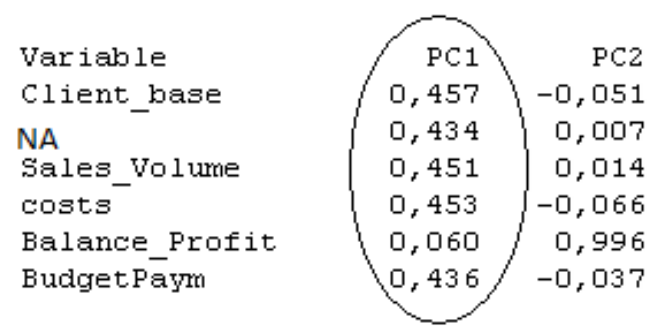

$\begin{array}{rr}\text { PC3 } & \text { PC4 } \\ -0,359 & -0,024 \\ -0,240 & 0,804 \\ 0,553 & -0,120 \\ 0,516 & -0,066 \\ -0,008 & -0,031 \\ -0,492 & -0,578\end{array}$

PC5
0,811
$-0,324$
0,017
$-0,063$
0,022
$-0,482$

\begin{tabular}{|c|c|c|c|}
\hline \multicolumn{4}{|c|}{ Eigenanalysis of the } \\
\hline Component & Eigenvalue & Proportion & Cumulative \\
\hline$\simeq I$ & 4,2807 & $0,7134=$ & 0,7134 \\
\hline 2 & 1,1715 & 0,1953 & 0,9087 \\
\hline 3 & 0,3155 & 0,0526 & 0,9613 \\
\hline 4 & 0,1914 & 0,0319 & 0,9932 \\
\hline 5 & 0,0379 & 0,0063 & 0,9995 \\
\hline 6 & 0,0029 & 0,0005 & 1,0000 \\
\hline
\end{tabular}

Figure 2. Modeling results in Gretl using the Principal Components Method for the year 2018

Eigenvectors (component loadings)
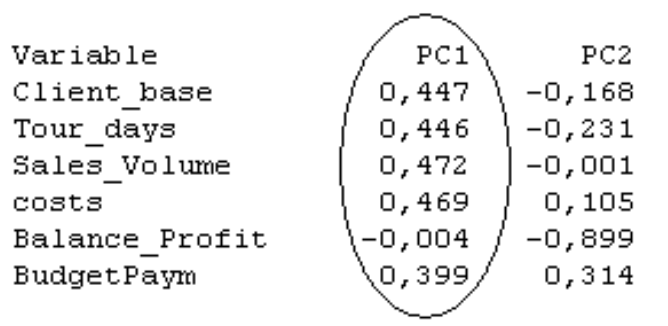

$\begin{array}{rrrr}\text { PC3 } & \text { PC4 } & \text { PC5 } & \text { PC6 } \\ -0,009 & 0,739 & 0,472 & -0,050 \\ 0,440 & 0,151 & -0,725 & 0,069 \\ 0,107 & -0,446 & 0,327 & 0,678 \\ 0,155 & -0,428 & 0,191 & -0,725 \\ -0,371 & -0,215 & 0,006 & -0,084 \\ -0,796 & 0,032 & -0,328 & 0,028\end{array}$

Figure 3. Modeling results in Gretl using the Principal Components Method for the year 2017 
The per cent of initial data $x_{1}, \ldots, x_{6}$ embraced by $y 1$ and included into the formula (4) is $71,34 \%$ (Proportion on fig 5).

Thus, eigenvalue $\lambda_{2017}=4,2807$ can be considered the rating of investment appeal for a region in 2017. Modeling results obtained above for the Crimean Region food industry investment appeal can be summarized as follows:

2017:

$$
Y 1_{2017}=0,447 \cdot \text { ClientBase }+0,446 \cdot N A+
$$$$
+0,472 \cdot \text { Sales Volume }+0,469 \cdot \text { Cost }-
$$

$-0,004 \cdot$ BalanceProfit +

$+0,399 \cdot$ BudgetPayments. $\lambda_{i}=4,2807$.
$Y 1_{2018}=0,457 \cdot$ ClientBase $+0,434 \cdot N A+$ 2018:

$+0,451 \cdot$ SalesVolume $+0,453 \cdot$ Costs +

$-0,06 \cdot$ BalanceProfit +

$+0,436 \cdot$ BudgetPayments. $\lambda_{i}=4,4692$.

$Y 1_{2019}=0,452 \cdot$ ClientBase $+0,428 \cdot N A+$ 2019:

$+0,459 \cdot$ SalesVolume $+0,453 \cdot$ Costs +

$+0,152 \cdot$ BalanceProfit +

$+0,416 \cdot$ BudgetPayments. $\lambda_{i}=4,3593$.

Model 1: OLS estimates using the 5 observations Dependent variable: rating

VARIABLE

COEFF ICIENT

$$
\begin{aligned}
& 3,79850 \\
& 0,135780
\end{aligned}
$$

STDERROR

$$
0,121144
$$$$
0,0365262
$$

T STAT

P-VALUE index

Mean of dependent variable $=4,20584$

Standard deviation of dep. var. $=0,236848$

sum of squared residuals $=0,040025$

Standard error of residuals $=0,115506$

Unadjusted R-squared $=0,821625$

Adjusted R-squared $=0,762167$

Degrees of freedom $=3$

Durbin-Watson statistic $=2,06425$

First-order autocorrelation coeff. $=-0,328039$

Log-likelihood $=4,97453$

Akaike information criterion (AIC) $=-5,94906$

Schwarz Bayesian criterion (BIC) $=-6,73018$

Hannan-Quinn criterion $(\mathrm{HQC})=-8,04552$

Figure 4. Trend modeling results for $\lambda_{i}$

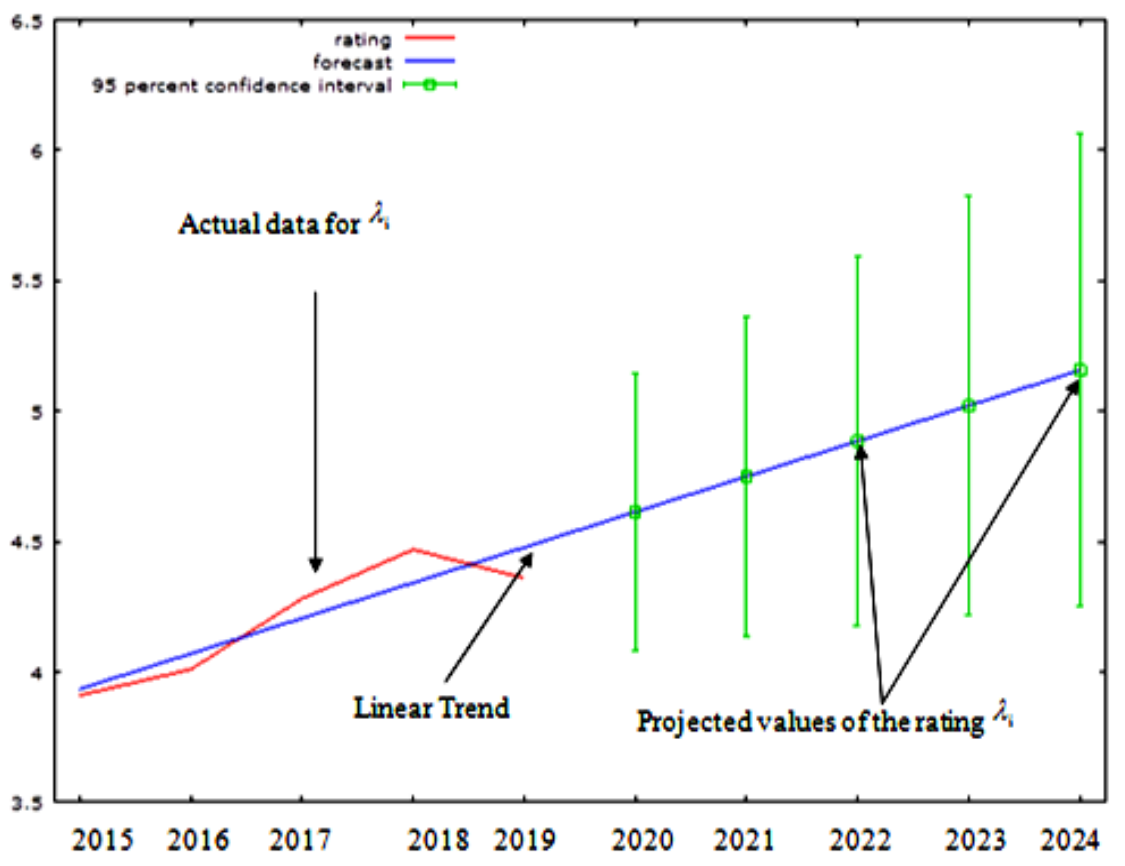

Figure 5. Dynamics and projection for $\lambda_{\mathrm{i}}$ (Crimea investment appeal rating) 
positive dynamics of individual financial and activity indicators of food companies in the region. generalization and synthesis of initial financial and activity indicators $x_{1}, \ldots, x_{6}$ for individual companies in a certain year into a generalized indicator of a company's investment appeal y1

(most significant principal component) and also for calculation of the investment appeal rating for a region's food industry $\lambda_{1}$ (eigenvalue for $\left.y 1.\right)$

In order to estimate the dynamics of the calculated ratings in the given time-frame (2015-2019) and to make the projections for the period (2020-2024), the trend analysis method (one of the methods for time series analysis) was applied in Gretl.

According to the modeling results using Ordinary Least Squares method (Figure 4) the trend model of the time series of $\lambda_{\mathrm{i}}$ was developed, formula (5):

$$
\lambda_{\mathrm{i}}=3,7985+0,13578 \cdot \mathrm{t}+\varepsilon,(5)
$$

where $\mathrm{t}$ - year; $\varepsilon$-random error (residuals).

Model (5) was developed based on prior obtained values of $\lambda_{2015}, \lambda_{2016}, \lambda_{2017}, \lambda_{2018}$.

Prediction of the rating $\lambda_{i}$ for the time frame (2020-2024) is shown on figure 5 and 6.

For $95 \%$ confidence intervals, $t(3, .025)=3,182$

Obs Prediction for std. error $95 \%$ confidence interval

\begin{tabular}{llll}
\multicolumn{5}{c}{$\lambda_{\text {i }}$ (Rating) } & & \\
2020 & 4,61318 & 0,167384 & $(4,08049,5,14587)$ \\
2021 & 4,74896 & 0,193279 & $(4,13386,5,36406)$ \\
2022 & 4,88474 & 0,222181 & $(4,17766,5,59182)$ \\
2023 & 5,02052 & 0,253061 & $(4,21517,5,82587)$ \\
2024 & 5,15630 & 0,285279 & $(4,24841,6,06419)$
\end{tabular}

Figure 6. The parameters of the projection for $\lambda_{\mathrm{i}}$ (Crimea investment appeal rating)

The model (5) can be considered adequate and its parameters - valid with a $5 \%$ probability of an error.

\section{CONCLUSION}

Overall positive dynamics of the investment appeal rating for Crimea can be indicated during the period 2015-2019, (Figure 5). The rating value is going to reach 4,61318 in 2020 and 5,15630 in 2024 according to the projections using the linear trend model (5).

Modeling results obtained in the research allow to make a conclusion that investment appeal of Crimea is going to increase $5,82 \%$ in 2020 and $18,28 \%$ in 2024 due to the

\section{REFERENCES}

[1] Ablaev, R.R., Kokodey, T.A., Lomachenko, T.I. Dynamics of the main factors of the global food crisis in history. Journal of Audit and financial analysis. 2020. № 1. pp. 181-186. DOI:

https://doi.org/10.38097/AFA.2020.79.34.025

[2] Berry, B.J.L. Long-wave Rhythms in Economic Development and Political Behaviour. Baltimore \& London. 1991.

[3] Braudel, F. The Perspective of the World. Civilization and Capitalism, 15th-18th Century. University of California Press, Berkeley. 1992.

[4] Carpenter, S., et al.: Ecosystems and human wellbeing: scenarios. findings of the Scenarios Working Group, Millennium Ecosystem Assessment. Island Press, Washington. 2005.

[5] Erokhina, E.V. Investment image and investment attractiveness of the region - the development of opportunities. Science and Modernity. 2016. № 4. pp. 20-33.

[6] Kokodey, T.A. History of the global business environment in the polycyclic conceptual framework. Applied Econometrics and International Development. 2013. №13 (2). pp. 1-17.

[7] Mustafakulov Sh. Investment Attractiveness of Regions: Methodical Aspects of the Definition and Classification of Impacting Factors. European Scientific Journal, 2017, vol. 13, no. 10, p. 433.

[8] Smaglyukova, T.M. Methodology for comprehensive assessment of investment attractiveness of regions in view of their sectoral specialization. Problems of Modern Economics. 2007. no. 3, pp. 311 314.

[9] Trachenko, M.B., Dzhioev, V.A. Express Analysis of the Investment Appeal of Regions. Finance and Credit. 2018. vol. 24. iss. 9. pp. 2151-2165.

[10] Yakovets, Y.: The Future of Civilizations and Strategy of Civilization Partnership. Part 9 of the Global Forecast "Future of Civilizations" for 2050. Moscow, Russia: SKII. 2009. 